\title{
Slagging characteristics caused by alkali and alkaline earth metals during municipal solid waste and sewage sludge co-incineration
}

\author{
Jing Zhao a, b, c, d, Bo Li ${ }^{\text {a, }}{ }^{*}$, Xiaolin Wei ${ }^{\text {a, c }}$, Yufeng Zhang a, c, Teng Li ${ }^{\text {a }}$ \\ a State Key Laboratory of High-Temperature Gas Dynamics, Institute of Mechanics, Chinese Academy of Sciences, Beijing, 100190, China \\ ${ }^{\mathrm{b}}$ Institute of Engineering Thermophysics, Chinese Academy of Sciences, Beijing 100190, China \\ c School of Engineering Science, University of Chinese Academy of Sciences, Beijing 100049, China \\ d Suzhou Hailu Heavy Industry Co.Ltd, Zhangiiagang, 215600, China
}

\section{A R T I C L E I N F O}

\section{Article history:}

Received 5 December 2018

Received in revised form

13 January 2020

Accepted 1 May 2020

Available online 3 May 2020

\section{Keywords:}

Municipal solid waste

Sludge

Co-incineration

Alkali and alkaline earth metals

Slagging

Sludge granulation

\begin{abstract}
A B S T R A C T
Municipal solid waste (MSW) and sewage sludge co-incineration is developing into a new method for sludge treatment. However, waste and sludge containing high levels of alkali and alkaline earth metals (AAEMs) will likely cause slagging, corrosion and deterioration of materials during incineration. The occurrence of AAEMs is studied through extraction experiments. Additionally, the surface microstructure and composition of samples are analyzed by SEM-EDS. XRF and XRD are used to analyze the content and crystalline phases of AAEMs. The experimental results indicate that slagging samples are characterized by high amounts of $\mathrm{Ca}, \mathrm{Na}, \mathrm{K}, \mathrm{Cl}$, and $\mathrm{S}$ elements. The samples contain numerous irregular particles due to the condensation and nucleation of AAEMs. The extraction experiments and XRD analyses indicate that the insoluble AAEMs are primarily Ca-diopside and gehlenite and $\mathrm{Na}$ and K-aluminosilicates in the furnace. The ammonium acetate-soluble Ca consists mainly of sulfates, and the water-soluble Na and $\mathrm{K}$ consist of alkali chlorides in the superheaters. In the reaction tower, AAEMs mainly exist as carbonates and the slagging mechanisms are caused by soda manufacture process. The transformation and deposition of AAEMs enhance the slagging and reduce the heat transfer efficiency. The release of AAEMs can be effectively decreased through using sludge granulation technology during MSW and sludge coincineration, and the furnace running time is extended.
\end{abstract}

(C) 2020 Elsevier Ltd. All rights reserved.

\section{Introduction}

In recent years, municipal solid waste (MSW) and sewage sludge co-incineration for energy generation has been used as an efficient method for the harmless treatment of sludge [1-3]. The thermal conversion of waste can realize the reduction, harmlessness and resource utilization of waste, which are of great significance for alleviating the problems of environmental pollution and energy shortage as a result of rapid economic development in China [4-6]. However, the main problem of MSW and sewage sludge coincineration is that the addition of sludge will increase the yield of ash containing high concentration of chlorine, sulfur, as well as alkali and alkaline earth metals (AAEMs), which will reduce the melting point of ash and enhance the slagging characteristics of ash $[7,8]$. However, most of previous studies [8-11] mainly focuses on

\footnotetext{
* Corresponding author.

E-mail address: libo@imech.ac.cn (B. Li).
}

the pollution cause by heavy metals and ignores the influence of AAEMs on incineration process. In wastes, all kinds of plastics, kitchen waste, building materials and sewage sludge may create high amounts of AAEMs, which will cause deposition, slagging, corrosion, and deterioration of materials during incineration $[12,13]$. The energy efficiency is also reduced due to formation of hard and voluminous deposits on the surfaces of heat-exchange facilities $[14,15]$. This results in reducing the stable running time, increasing operational hazards and decreasing economic benefit.

During incineration, some alkali/alkaline metals can react with silicon aluminum oxides to form relatively high melting point compounds $[16,17]$. In addition, $\mathrm{Ca}, \mathrm{Na}$ and $\mathrm{K}$ are generally released as $\mathrm{CaCl}_{2}, \mathrm{NaCl}$ and $\mathrm{KCl}[18,19]$, and alkali/alkaline metal sulfates are produced in the presence of sulfur in effluent gas [20,21]. These sulfates are more stable than chlorides. Alkali/alkaline metal chlorides and sulfates are inclined to deposit on the surface of facilities [22-24], which can cause corrosion of facilities. At present, the behavior of AAEMs has been studied to some extent during pure MSW incineration. Yu et al. [25] studied the solid residues 
originating from CFB combustion of MSW through a detailed physical and chemical characterization and found that the major compounds in the bottom ashes and fly ashes were $\mathrm{CaCO}_{3}, \mathrm{CaICl}_{2}$, $\mathrm{CaSO}_{4}, \mathrm{NaCl}$ and $\mathrm{KCl}$. Tortosa et al. [26] reported that ash rich in $\mathrm{NaCl}$ and $\mathrm{KCl}$ could decrease the ash melting point, plant efficiency and availability by evaluating the validity of thermal analysis methods to characterize the fusion of biomass and waste ashes. Lebel et al. [27] confirmed that the sulfates formed by $\mathrm{Na}$, K and $\mathrm{Ca}$ were the main corrosion deposits via simultaneous simulation of the temperature gradient at the flue-gas/tube interface, and the velocities of flue-gas and ash in a laboratory-scale corrosion pilot. Brossard et al. [28] also reported that combustion of municipal waste would generate highly corrosive gases, such as $\mathrm{HCl}, \mathrm{SO}_{2}, \mathrm{NaCl}$, $\mathrm{KCl}$, and heavy metals chlorides. However, few studies can systematically report the migration and deposition of AAEMs from furnace to reaction tower and slagging phenomenon caused by AAEMs during MSW and sewage sludge co-incineration. Compared with conventional MSW, sludge contains higher concentrations of $\mathrm{Cl}$ and $\mathrm{S}$, in addition to $\mathrm{Ca}, \mathrm{Na}$ and $\mathrm{K}[16,29]$, which can promote the release of AAEMs [18,30,31], and then enhance the slagging and corrosion phenomena [32,33].

Because of the complex composition of the wastes, it is difficult to directly study the migration of AAEMs and the slagging phenomenon caused by AAEMs under laboratory conditions. Lin et al. [34] tried to simulate the procedure of co-incineration of sewage sludge with MSW in a full-scale grate furnace incinerator. They found that the simulation results can reflect the actual operating conditions, and also prove the reliability of the mathematical and physical model. Based on the FactSage thermodynamic calculation package and databases, Poole, et al. [35] predicted the equilibrium composition of the solid, liquid and gaseous products from municipal solid waste incineration. They thought an increase in alkali content is predicted to increase the amount of gaseous species involving alkali metals and the amount of slag is also increased. Otsuka [32] also conducted a thermodynamic equilibrium calculation to understand the effects of tube wall temperature, flue gas temperature, and waste chemistry on the type and amount of vapor-condensed "corrosive" salts and found that chlorine, sulfur, sodium, potassium, and calcium contents in waste affected the deposition formation.

Although the calculation can better predict the incineration process of waste, the migration and deposition of mineral elements such as AAEMs and how to cause slagging phenomenon are not completely and accurately presented. To fully understand and reveal the actual slagging and corrosion mechanism in facilities, such as furnace, heat exchangers and reaction tower, the release, transformation and deposition paths of AAEMs are indirectly inferred through investigating the occurrence mode and crystal structure of AAEMs in slagging samples at different positions. Accordingly, AAEMs can be categorized into four occurrence modes according to a sequential extraction method [36]: water soluble (deionized water), exchangeable (ammonium acetate), acid soluble (hydrochloric acid) and acid insoluble (aqua regia). The watersoluble alkali metals ( $\mathrm{NaCl}, \mathrm{KCl}$, and $\mathrm{Na}_{2} \mathrm{SO}_{4}$ etc.) and acetatesoluble alkaline earth metal $\left(\mathrm{CaSO}_{4}\right)$ are usually the main forms that cause the slagging and corrosion [37-40]. The addition of sewage sludge rich in $\mathrm{Cl}$ and $\mathrm{S}$ into waste will promote the release of AAEMs during MSW incineration. Therefore, there is an urgent need to develop a method for pretreatment of sludge to reduce the release of $\mathrm{Cl}$ and $\mathrm{S}$ during incineration.

The aim of this paper is to study the release, transformation and deposition paths of AAEMs during MSW and sludge co-incineration and formation mechanisms of slagging samples that are obtained from four different positions: furnace, high-temperature superheater, medium-temperature superheater and reaction tower.
Firstly, scanning electron microscopy-energy dispersive spectrometry (SEM-EDS) and X-ray fluorescence (XRF) are used to analyze the surface microstructures and the content of elements. The occurrence modes of AAEMs and the contents can be determined by chemical extraction methods. The detailed crystalline phases of AAEMs are studied by X-ray diffraction (XRD). Secondly, the release and migration paths of AAEMs are predicted based on the above results. Particularly, the mechanisms of transformation and slagging of AAEMs in the furnace, superheaters and reaction tower are discussed. Finally, during the actual operation of the plant, the paper discusses how sludge granulation affects the release of AAEMs and furnace running time through studying three different waste feeding methods, such as pure waste, waste and sludge, as well as waste and granulated sludge. And the effectiveness and practicality of sludge granulation are evaluated during actual MSW and sewage sludge co-incineration.

\section{Experimental section}

\subsection{Experimental materials}

Waste (90\%) mixed with sludge (10\%) incineration takes place in the combustion chamber on a moving grate (as shown in Fig. 1(a)), which located in Yantai, Shandong, China, which handles 580 tons of MSW, which includes all kinds of plastics (approximately 6.8\%), kitchen waste (approximately 33.4\%), yard waste (approximately $10.6 \%$ ), paper (approximately 6.7\%), fabric (approximately $4.2 \%$ ), glass (approximately 2.3\%), metals (approximately $2.5 \%$ ), building materials (approximately 27.4\%) and others (approximately 6.1\%).

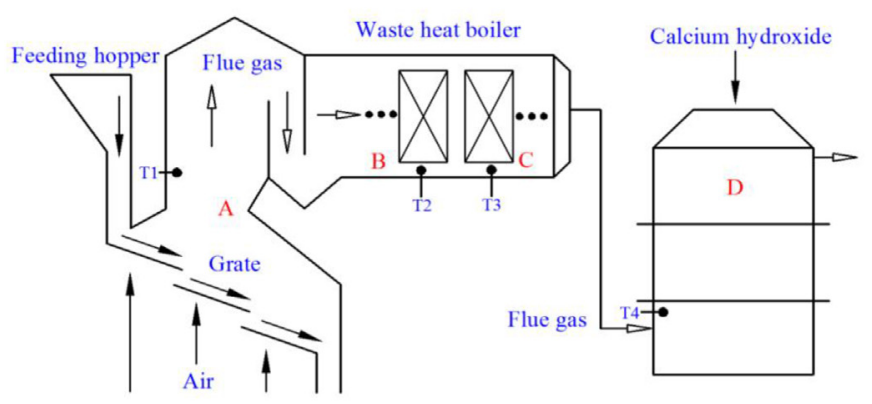

(a)

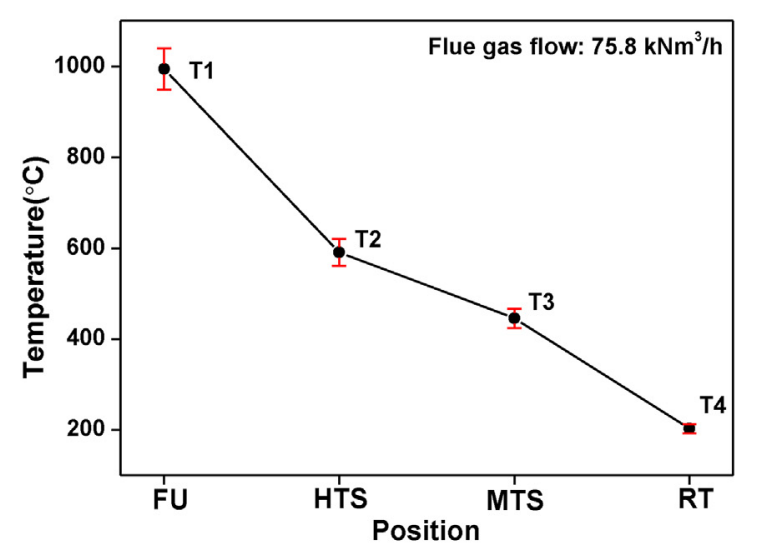

(b)

Fig. 1. (a) Schematic of the waste-to-energy facility located in Yantai, Shandong, China: (A) furnace, (B) high-temperature superheater, (C) medium-temperature superheater, and (D) reaction tower. (b) Gas temperature corresponding to the slagging position. 
According to the results provided by plant laboratory, the mass fraction of AAEMs is approximately $2.62-4.28 \%$, that of $\mathrm{Cl}$ is approximately $0.11-0.35 \%$, and that of $S$ is approximately $0.14-0.43 \%$. Primary air is injected through the grate and secondary air is introduced through the wall of the furnace chamber. The walls of the combustion chamber are made of evaporator tubes (waterwall) producing saturated steam going to the drum. Incineration gases including AAEMs, leave the furnace at a temperature near $1173 \mathrm{~K}$, and go through the waste heat boiler pass, where several types of heat-exchangers are positioned. After that, the flue gas will enter the reaction tower for deacidification. Samples as received from A, B, C and D in Fig. 1(a) are ground to powder and sieved to particle sizes between 60 and $105 \mu \mathrm{m}$, named FU, HTS, MTS, and RT, respectively. The samples are dried at $378 \mathrm{~K}$ for $2 \mathrm{~h}$ and stored as experimental samples. The gas temperatures of the sample positions are shown in Fig. 1(b).

The composition analysis of slagging samples is listed in Table 1. Obviously, slagging samples are characterized by high levels of $\mathrm{Ca}$, $\mathrm{Na}$ and $\mathrm{K}$. For example, the Ca content of the high-temperature surface of superheater is approximately 30\% and the content is $10 \%$ for alkali metals ( $\mathrm{Na}$ and $\mathrm{K}$ ). In addition, the Na content in the slagging sample is relatively high in the reaction tower, indicating that a large amount of $\mathrm{Na}$ in the flue gas is captured during deacidification. This process will seriously cause alkali corrosion to the equipment and affect the safe operation of facilities.

The sewage sludge treated by waste-to-energy plants mainly comes from domestic wastewater treatment. The physicochemical properties of the sludge feedstock used in this work are shown in Table 2. The sludge is not only rich in AAEMs, but also contains high contents of $\mathrm{Cl}$ and $\mathrm{S}$. Sludge addition further aggravates the release of AAEMs, which will cause serious slagging and corrosion of the equipment. This process increases the operational risks of the equipment and reduces the economic benefits.

\subsection{Experimental procedures}

\subsubsection{Chemical extraction experiments}

All the sieved slagging samples are dried again in an oven at $378 \mathrm{~K}$ in a $\mathrm{N}_{2}$ atmosphere for $1 \mathrm{~h}$ before conducting the experiments. Based on the study of Benson [41] on low-rank coals, a fourstep sequential extraction method is employed. Water soluble: $0.5 \mathrm{~g}$ slagging samples and $50 \mathrm{ml}$ deionized water are mixed in a $100 \mathrm{ml}$ polyethylene centrifuge tube. Then, the tube is placed in a $333 \mathrm{~K}$ water bath at a constant temperature for more than $24 \mathrm{~h}$ with centrifugation at $200 \mathrm{rpm} / \mathrm{min}$. The water soluble $\mathrm{Ca}$, Na and $\mathrm{K}$ analysis can be determined by the washing solution. The residue is used for the next step. Exchangeable: $50 \mathrm{ml}$ of the $1 \mathrm{~mol} / \mathrm{L} \mathrm{NH}_{4} \mathrm{OAc}$ buffer solution is added to the residue and the above operation is repeated. Acid soluble: the solution used for the residue is $1 \mathrm{~mol} / \mathrm{L}$ $\mathrm{HCl}$, and the step is the same as that of the exchangeable step. The measured $\mathrm{Ca}, \mathrm{Na}$ and $\mathrm{K}$ are acid soluble. The residue collected from the above step is dried in an oven at $378 \mathrm{~K}$ in a $\mathrm{N}_{2}$ atmosphere for $1 \mathrm{~h}$ and then digested by using $\mathrm{HNO}_{3}$ and $\mathrm{HF}$. Later, the vessel is heated to $493 \mathrm{~K}$ and kept at that temperature for $1 \mathrm{~h}$. Then the solution is diluted to $100 \mathrm{~mL}$ for $\mathrm{Ca}$, $\mathrm{Na}$ and $\mathrm{K}$ measurement, and the results show the acid insoluble AAEMs. In each step, the $\mathrm{Ca}, \mathrm{Na}$ and
Table 2

Physicochemical properties of the sludge (dry basis).

\begin{tabular}{lcc}
\hline Item & Unit & Value \\
\hline Proximate analysis (dry basis) & & \\
Ash & wt.\% & 35.173 \\
Volatile matter & wt.\% & 55.487 \\
Fixed carbon & wt.\% & 9.34 \\
Ultimate analysis (dry basis) & & \\
$\mathrm{C}$ & $\mathrm{wt} . \%$ & 22.07 \\
$\mathrm{H}$ & $\mathrm{wt.} \%$ & 5.538 \\
$\mathrm{O}$ & $\mathrm{wt} . \%$ & 31.26 \\
$\mathrm{~N}$ & $\mathrm{wt} . \%$ & 3.6 \\
$\mathrm{~S}$ & $\mathrm{wt} . \%$ & 1.379 \\
$\mathrm{Cl}$ & $\mathrm{wt} . \%$ & 0.98 \\
$\mathrm{Mineral} \mathrm{composition} \mathrm{(dry} \mathrm{basis)}$ & & \\
$\mathrm{Ca}$ & $\mathrm{mg} / \mathrm{g}$ & 31.52 \\
$\mathrm{Na}$ & $\mathrm{mg} / \mathrm{g}$ & 3.61 \\
$\mathrm{~K}$ & $\mathrm{mg} / \mathrm{g}$ & 5.01 \\
\hline
\end{tabular}

$\mathrm{K}$ species that dissolved in solutions, are measured by an ICAP 6000 Series. A weight basis is used for presentation of the contents of AAEMs. The relative standard deviation (RSD) is controlled within $5 \%$ by performing three replicates of the samples.

\subsubsection{Characterization methods}

A scanning electron microscope (JSM-7800 F, JEOL, Japan) with a scanning electron microscopy-energy dispersive spectrometer (SEM-EDS) with the typical accelerating voltage of $20 \mathrm{kV}$, is used to observe the morphology and composition of slagging samples. The contents are analyzed by XRF using an energy dispersive instrument (E3, Netherlands) with $0.05 \%$ error. The crystalline phase analysis is determined by powder XRD using a Rigaku D/MAC/max $2500 \mathrm{v} / \mathrm{pc}$ instrument (DX2700, China) with $\mathrm{Cu}$ Ka radiation $(40 \mathrm{Kv}$, $200 \mathrm{~mA}, \lambda=1.5418 \mathrm{~A}$ ) with $0.05 \%$ error. Diffractometer data is acquired with a step size of $0.02^{\circ}$ for $2 \theta$ values from 5 to $80^{\circ}$. The crystalline phases are analyzed based on the Jade 6.0 database.

\section{Results and discussion}

\subsection{Morphology and composition of slagging samples}

AAEMs are released from the fuel into the flue gas during incineration and are inclined to combine with fly ash, which results in reducing the melting point and promoting the conversion of ash into slag [26-28]. When gas enters the waste heat boiler, as the temperature decreased, AAEMs precipitate from the effluent gas and condenses on the high-temperature surface of the heat exchangers or other facilities, causing slagging and corrosion. The detailed images of slagging morphology obtained from SEM are shown in Fig. 2. The surface of slagging samples is inhomogeneous and contains numerous irregular particles. EDS analysis can determine the compositions and contents of the four slagging samples. Yu et al. [42] thought that the surface micrographs of samples rich in $\mathrm{Ca}$ and $\mathrm{Cl}$ contained numerous irregular materials, and homogeneous and smoother crystallites were characteristic of high amounts of $\mathrm{Cl}, \mathrm{S}, \mathrm{Na}$ and $\mathrm{K}$. The sample collected from the furnace is characterized as high amounts of $\mathrm{Ca}, \mathrm{Al}, \mathrm{Si}, \mathrm{Mg}$, etc.

Table 1

Ash analysis of slagging sample compositions (wt.\%).

\begin{tabular}{|c|c|c|c|c|c|c|c|c|c|c|c|}
\hline Sample & $\mathrm{CaO}$ & $\mathrm{MgO}$ & $\mathrm{Na}_{2} \mathrm{O}$ & $\mathrm{K}_{2} \mathrm{O}$ & $\mathrm{Fe}_{2} \mathrm{O}_{3}$ & $\mathrm{Al}_{2} \mathrm{O}_{3}$ & $\mathrm{SiO}_{2}$ & $\mathrm{TiO}_{2}$ & $\mathrm{SO}_{3}$ & $\mathrm{P}_{2} \mathrm{O}_{5}$ & $\mathrm{Cl}$ \\
\hline $\mathrm{FU}$ & 26.357 & 3.62 & 3.08 & 1.38 & 8.489 & 12.615 & 39.514 & 1.356 & 0.359 & 2.291 & 0.172 \\
\hline HTS & 27.256 & 3.893 & 5.05 & 5.344 & 3.141 & 2.975 & 12.999 & 0.528 & 27.096 & 1.016 & 6.518 \\
\hline MTS & 32.392 & 2.968 & 4.15 & 5.14 & 4.083 & 4.421 & 6.286 & 0.963 & 30.045 & 1.716 & 4.323 \\
\hline RT & 29.331 & 3.418 & 20.942 & 0.8 & 1.82 & 2.792 & 6.125 & 0.408 & 7.503 & 0.909 & 1.517 \\
\hline
\end{tabular}



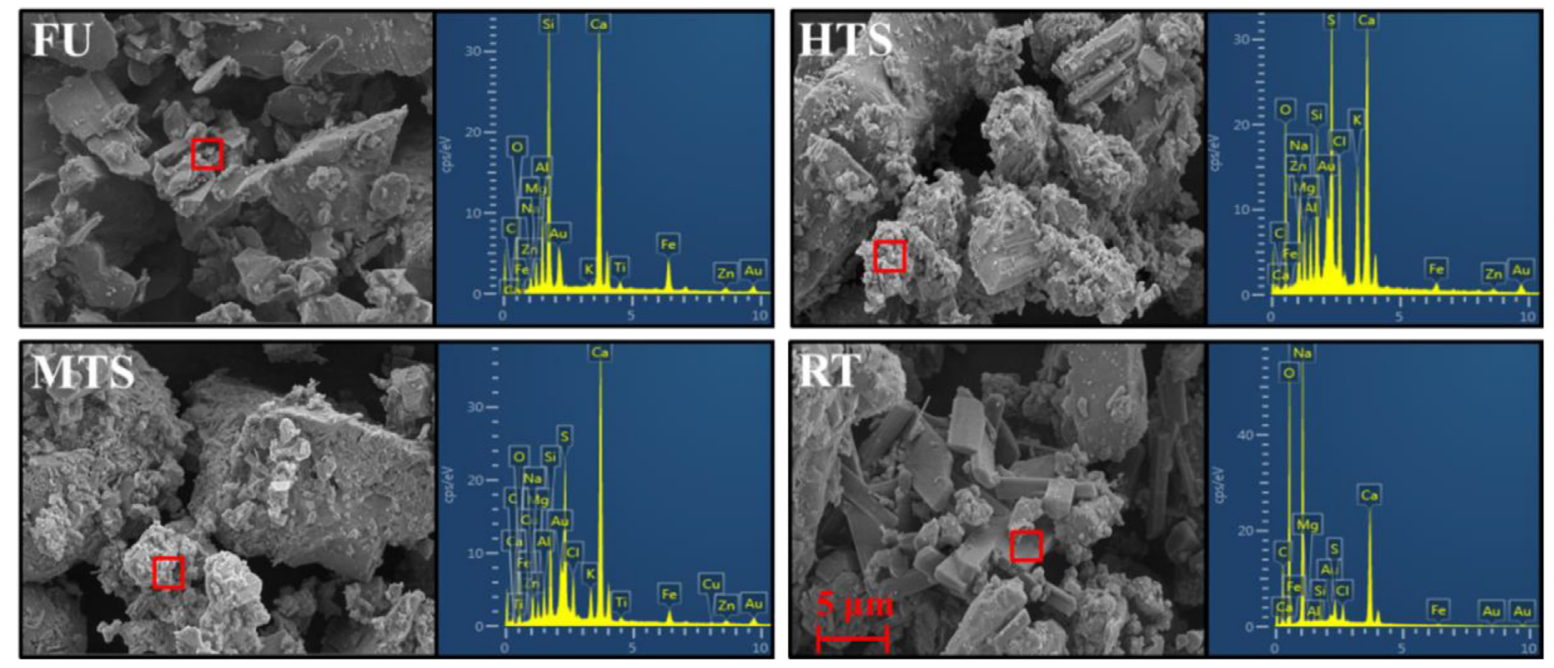

Fig. 2. Results of SEM-EDS for four slagging samples during incineration.

elements. The two samples obtained from the high-temperature and medium-temperature superheaters are mainly composed of $\mathrm{Ca}$, S, etc. elements, which has been also confirmed by some other researchers $[37,43]$. The slag from the reaction tower is characterized by high concentrations of $\mathrm{Na}$, $\mathrm{Ca}$, etc. elements. However, there are few reports on the slagging phenomenon in the reaction tower. As determined by EDS in the FU, the hardness of the slag is very high and contains many glassy crystallites and irregular materials due to relatively high contents of $\mathrm{Ca}$ and $\mathrm{Si}$. Comparatively, $\mathrm{Ca}$ and $\mathrm{S}$ are enriched in HTS and MTS, and the morphology is inhomogeneous, indicating the presence of sulfates of $\mathrm{Ca}$. The positions characterized as high amounts of Ca and Na in the RT, are relatively smooth. Therefore, it can be inferred that the irregular particles may be formed by the condensation, nucleation or coagulation of AAEMs [40].

As shown in Fig. 3, the results obtained from slagging compositions and EDS analysis are consistent with the conclusions determined by XRF, which indicate that the contents of AAEMs are relatively high in the slagging samples. According to Song et al. [44] and Oleschko et al. [45], alkali metals were easily released in the form of chloride or sulfate. Therefore, the content of $\mathrm{Na}, \mathrm{K}, \mathrm{Cl}$ and $\mathrm{S}$

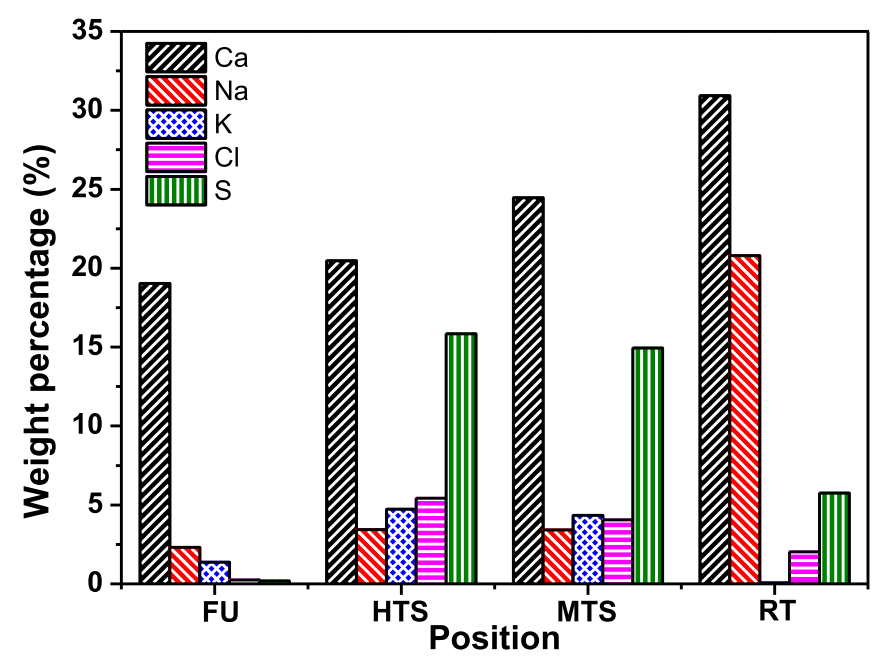

Fig. 3. Contents of $\mathrm{Ca}, \mathrm{Na}, \mathrm{K}, \mathrm{Cl}$ and $\mathrm{S}$ in four slagging samples. in the FU is relatively low, and the main reason is that alkali metals can be released into the flue gas with the release of $\mathrm{Cl}$ and $\mathrm{S}$ during incineration. In addition, Qi, et al. [46] found that minerals such as $\mathrm{Si}$ and $\mathrm{Al}$ can inhibit the release of alkali metals by forming high melting point of aluminosilicate. The measured results also indicate that a small amount of alkali metals still exists in the furnace, which proving that a small amount of gas phase alkali metals may react with silicon aluminum oxide to form aluminosilicate. The alkaline earth metal Ca can also react with $\mathrm{SiO}_{2}$, etc. to form a low melting point compound at a high temperature, which can adheres to the furnace, which is confirmed by Poole et al. [35] and Okuno et al. [47]. Therefore, the content of Ca is relatively high and reached to $19 \%$ in the furnace. The slagging samples collected form superheaters are mainly consisted of Ca and S. Compared with HTS, as the gas temperature decreased in the MTS, the deposition process of AAEMs on the surface of the superheater is enhanced, which indicate that the temperature has an important role in the condensation of gaseous AAEMs [40]. For example, the content of Ca is increased from $20.47 \%$ to $24.45 \%$ with reducing the gas temperature. Moreover, some of the alkali metals $\mathrm{Na}$ and $\mathrm{K}$ also precipitate from the flue gas and adhere to the heat exchanger, which is also proved by Lebel et al. [27]. In the RT, slurry is employed to realize deacidification during incineration, so the content of $\mathrm{Ca}$ is relatively high in the slagging sample. In addition, the weight percentage of $\mathrm{Na}$ reaches to $20.8 \%$, which indicating that alkali metal $\mathrm{Na}$ can be trapped from the gas during deacidification, resulting in slagging and deterioration of materials.

\subsection{Occurrence modes of AAEMs in slagging samples}

The total amount of $\mathrm{Ca}, \mathrm{Na}$ and $\mathrm{K}$ determined in each step (the stack column) and the total contents of $\mathrm{Ca}$, $\mathrm{Na}$ and $\mathrm{K}$ via microwave digestion in the slagging samples (denoted by asterisks), are described in Fig. 4. The results of the extraction experiments indicate that most of the $\mathrm{Ca}, \mathrm{Na}$ and $\mathrm{K}$ are acid-insoluble, approximately accounting for $90.8 \%, 93 \%$, and $92.3 \%$ of the total content, respectively in the FU. And the amount of $\mathrm{Ca}$, Na and $\mathrm{K}$ in water-soluble, ammonium acetate-soluble and acid-soluble modes is relatively low in comparison to the existing forms of insoluble AAEMs. According to Phongphiphat et al. [48], the slagging samples consisting of AAEMs are mainly generated by reaction between $\mathrm{Ca}, \mathrm{Na}$, and $\mathrm{K}$ and silicon aluminum oxide in the FU. However, for the slagging samples from the high-temperature surface of the superheaters, $\mathrm{Ca}$ 


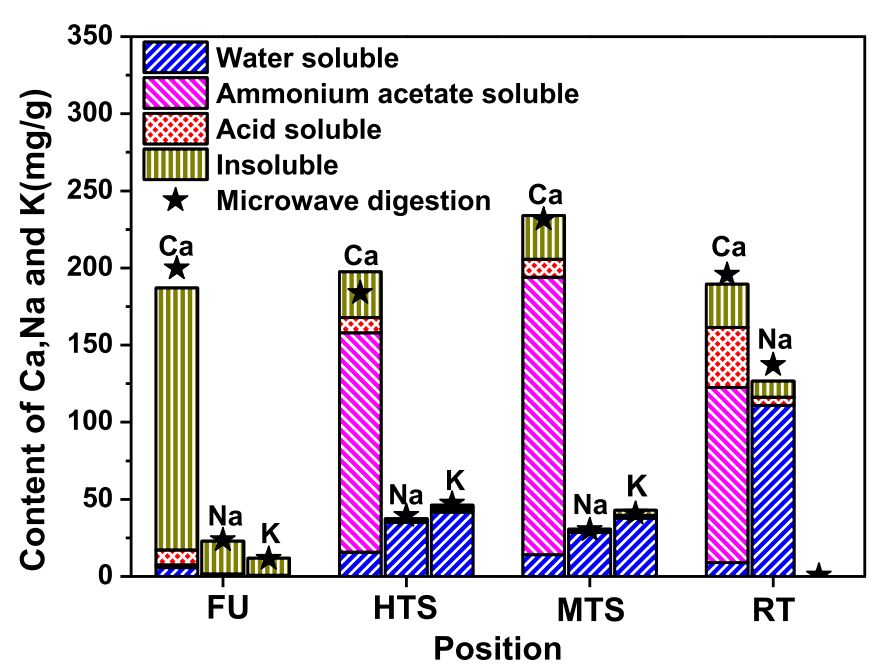

Fig. 4. Summation of AAEMs contents using different extraction methods.

is mainly present in the ammonium acetate-soluble form, and $\mathrm{Na}$ and $\mathrm{K}$ are mainly present in the water-soluble mode. For example, in the HTS, the acetate-soluble form of Ca approximately accounts for $72 \%$, and the water-soluble forms of $\mathrm{Na}$ and $\mathrm{K}$ approximately accounts for $94 \%$ and $90 \%$, respectively. This is mainly because AAEMs are easily volatilized into the flue gas in the form of chlorides and sulfates during incineration and similar conclusion is also gained by Brossard et al. [28] and Otsuka [32]. And as the gas temperature decreased due to waste heat recovery in the waste heat boiler, the AAEMs will condense and deposit on the surface of the superheaters. For example, compared with HTS, the content of ammonium acetate-soluble Ca increases about $21 \%$ in the MTS, indicating that gaseous $\mathrm{Ca}$ can precipitate from the flue gas with decreasing temperature. In addition, acid-soluble and insoluble AAEMs did not observably increase, indicating that they are present when the slagging samples are initially formed and did not obviously precipitate from the flue gas. For the slagging sample collected from the RT, the results are similar to those of HTS and MTS. The conclusions indicate that Ca mainly exists in the form of ammonium acetate-soluble form, and $\mathrm{Na}$ is mainly water-soluble. The alkali metal $\mathrm{K}$ is not found in the slagging sample, indicating that $\mathrm{K}$ is not trapped in the RT. In addition, the content of acidsoluble Ca increases, indicating that other types of Ca compounds form during deacidification.

\subsection{Crystalline phase analysis of AAEMs in slagging samples}

As shown in Fig. 5, XRD analyses are conducted to determine the main crystalline phase to study the detailed compositions and compounds in the four slagging samples. The absorbance band areas of each crystalline phase are related to their percentages [49]. Acid-insoluble diopside $\left(\mathrm{Ca}_{2} \mathrm{MgFeSi}_{4} \mathrm{O}_{12}\right)$, gehlenite $\left(\mathrm{Ca}_{2} \mathrm{MgAl}_{2}\right.$ $\left.\mathrm{Si}_{2} \mathrm{O}_{10}\right)$ and sodium and potassium aluminum silicates $\left(\mathrm{NaAlSi}_{2} \mathrm{O}_{6}\right.$, $\mathrm{KAISi}_{2} \mathrm{O}_{6}$ ) make up the main AAEM phases in the FU; however, other occurrence forms of AAEMs are relatively small. In addition, some AAEMs will be released in the form of chloride as $\mathrm{CaCl}_{2}, \mathrm{NaCl}$ or $\mathrm{KCl}$ during incineration [18,50]. In the HTS and MTS, the Na and $\mathrm{K}$ crystalline phases are alkali chlorides, such as $\mathrm{NaCl}$ or $\mathrm{KCl}$, whereas the Ca crystalline phases are mainly sulfates, indicating that $\mathrm{CaCl}_{2}$ is sulfated in the presence of $\mathrm{SO}_{2}$ or $\mathrm{SO}_{3}$ during incineration. This conclusion is consistent with that of XRF analysis in Fig. 3. Considering that the melting point of $\mathrm{CaCl}_{2}$ is $1055 \mathrm{~K}$, that of $\mathrm{NaCl}$ is $1074 \mathrm{~K}$ and that of $\mathrm{KCl}$ is $1043 \mathrm{~K}$, when the gas temperature exceeds

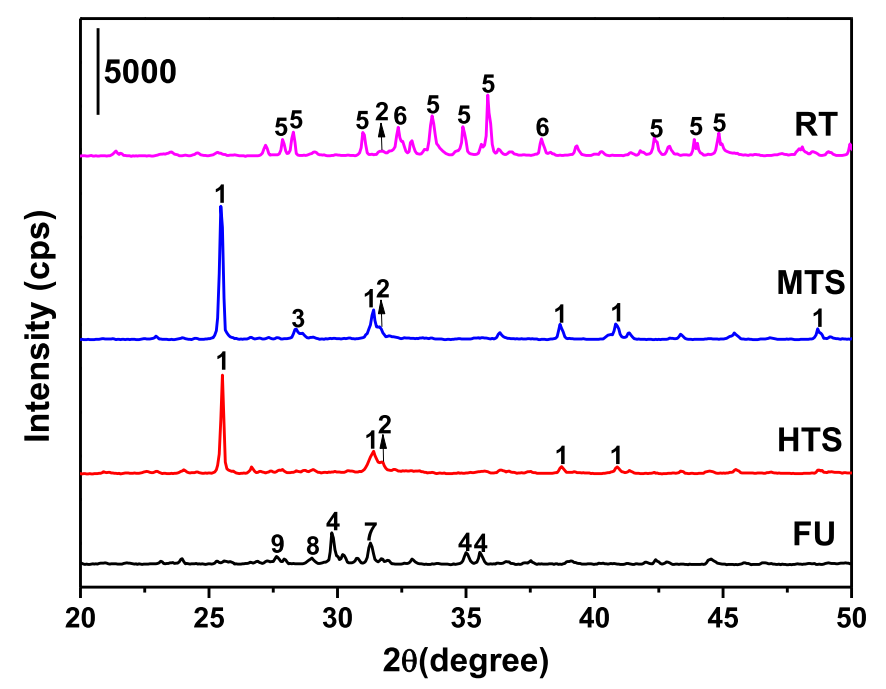

Fig. 5. XRD patterns of four slags during MSWI. The main crystalline phases can be shown as (1) Anhydrite $\mathrm{CaSO}_{4}$, (2) Halite $(\mathrm{NaCl})$, (3) Sylvite $(\mathrm{KCl})$, (4) Diopside $\left(\mathrm{Ca}_{2} \mathrm{MgFeSi}_{4} \mathrm{O}_{11}\right)$, (5) Pirssonite $\left(\mathrm{CaNa}_{2}\left(\mathrm{CO}_{3}\right)_{2} \cdot 2 \mathrm{H}_{2} \mathrm{O}\right)$, (6) Sodium carbonate hydrate $\left(\mathrm{Na}_{2} \mathrm{CO}_{3} \cdot \mathrm{H}_{2} \mathrm{O}\right)$, (7) Gehlenite $\left(\mathrm{Ca}_{2} \mathrm{MgAl}_{2} \mathrm{Si}_{2} \mathrm{O}_{10}\right)$, (8) Sodium aluminum silicate (NaAl$\mathrm{Si}_{2} \mathrm{O}_{6}$ ), and (9) Potassium aluminum silicate $\left(\mathrm{KAlSi}_{2} \mathrm{O}_{6}\right)$.

the melting point of the reactants, the gaseous reaction plays an important role in the sulfation of $\mathrm{CaCl}_{2}, \mathrm{NaCl}$, and $\mathrm{KCl}$. The main reaction is as follows: $2 \mathrm{CaCl}_{2}(\mathrm{~g})+2 \mathrm{SO}_{2}(\mathrm{~g})+2 \mathrm{H}_{2} \mathrm{O}(\mathrm{g})+\mathrm{O}_{2}$ $(\mathrm{g})=2 \mathrm{CaSO}_{4}(\mathrm{~s})+4 \mathrm{HCl}(\mathrm{g})$, where the $\mathrm{CaCl}_{2}$ can be replaced by $\mathrm{NaCl}$ and $\mathrm{KCl}$. However, alkali metal ( $\mathrm{Na}$ or $\mathrm{K}$ ) sulfates are not obviously found, indicating that $\mathrm{CaCl}_{2}$ might be able to undergo displacement reactions with alkali metal sulfates to inhibit their formation, which is also confirmed by Pyykönen et al. [23]. In the $\mathrm{RT}$, The main crystalline phases are pirssonite $\left(\mathrm{CaNa}_{2}\left(\mathrm{CO}_{3}\right)_{2} \cdot 2 \mathrm{H}_{2} \mathrm{O}\right)$ and sodium carbonate hydrate $\left(\mathrm{Na}_{2} \mathrm{CO}_{3} \cdot \mathrm{H}_{2} \mathrm{O}\right)$. Before the flue gas enters the reaction tower, most of the $\mathrm{CaSO}_{4}$ has deposited in the flue gas, and $\mathrm{NaCl}$ and residual $\mathrm{NH}_{3}$ react with the lime slurry $\left(\mathrm{Ca}(\mathrm{OH})_{2}\right)$ during the deacidification process in the RT. When the gas temperature is relatively low, R1-R3 can become dominant due to Hou's process (for soda manufacture). This result also indicates the reason that peak positions of $\mathrm{NaCl}$ disappear in the RT slag. The major reactions can be expressed as follows:

$$
\begin{aligned}
& \mathrm{NaCl}(\mathrm{s})+\mathrm{NH}_{3}(\mathrm{~g})+\mathrm{CO}_{2}(\mathrm{~g})+\mathrm{H}_{2} \mathrm{O}(\mathrm{l})=\mathrm{NaHCO}_{3}(\mathrm{~s})+\mathrm{NH}_{4} \mathrm{Cl}(\mathrm{g}) \\
& 2 \mathrm{NaHCO}_{3}(\mathrm{~s})=\mathrm{Na}_{2} \mathrm{CO}_{3} \cdot \mathrm{H}_{2} \mathrm{O}(\mathrm{s})+\mathrm{CO}_{2}(\mathrm{~g}) \\
& \mathrm{Ca}(\mathrm{OH})_{2}(\mathrm{~s})+2 \mathrm{NaHCO}_{3}(\mathrm{~s})=\mathrm{CaNa}_{2}\left(\mathrm{CO}_{3}\right)_{2} \cdot 2 \mathrm{H}_{2} \mathrm{O}(\mathrm{s})
\end{aligned}
$$

Fig. 5 also presents the various band positions for the main crystalline phases in the four slagging samples. For example, the diopside bands in the FU are mainly characterized by peaks at $29.8^{\circ}$, $35.0^{\circ}$, and $35.5^{\circ}$; the anhydrite bands in the HTS and MTS are found in peaks at $25.4^{\circ}, 31.3^{\circ}, 38.6^{\circ}$, and $40.8^{\circ}$; and the pirssonite bands in the RT show peaks at $28.2^{\circ}, 33.6^{\circ}$ and $35.8^{\circ}$. The different bands of each crystalline phase indicate that the crystal structure planes are

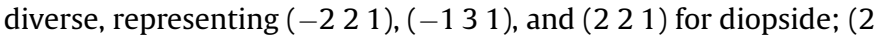
00 ), (1 02 2), (2 02 ), and (1 22 2) for anhydrite; and (3 11 ), (2 02 2), and (351) for pirssonite. The main absorbance band is characterized by a peak at $29.8^{\circ}$ for diopside, $25.4^{\circ}$ for anhydrite, and $33.6^{\circ}$ and $35.8^{\circ}$ for pirssonite. This is the main key positions that cause the content of $\mathrm{Ca}, \mathrm{Na}$, and $\mathrm{K}$ to increase in the slagging samples.

Based on XRD results, Fig. 6 illustrates the total $\mathrm{Ca}, \mathrm{Na}$ and $\mathrm{K}$ contents as determined by XRF and chemical extraction 


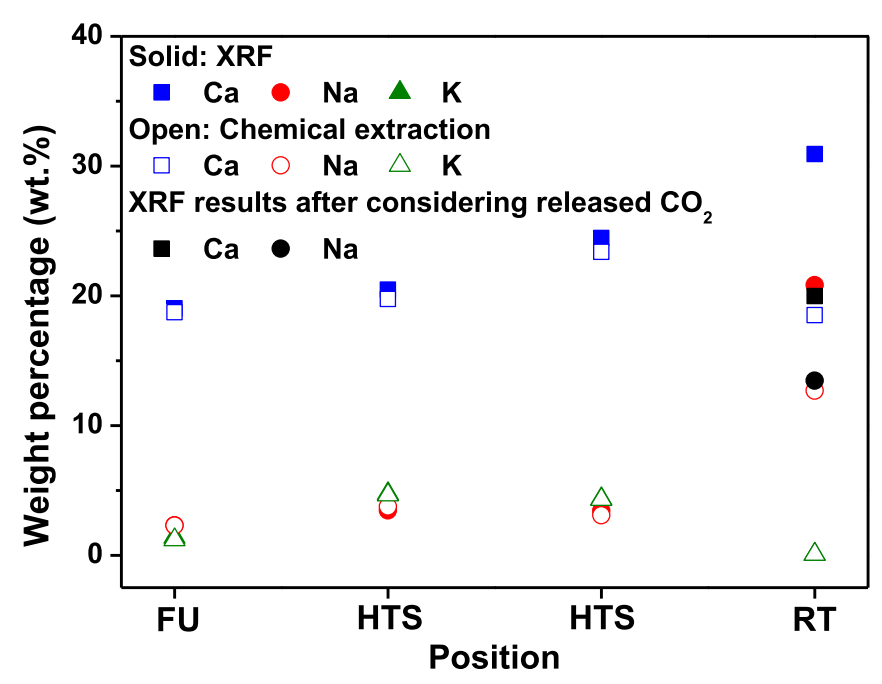

Fig. 6. Comparison of AAEM contents determined by XRF and chemical extraction.

experiments, respectively. The results gained from XRF are consistent with those of chemical extraction in the FU, HTS and MTS, except for RT. The contents of Ca and Na determined by XRF are $30.9 \%$ and $20.8 \%$, respectively, while that determined by chemical extraction are $18.5 \%$ and $12.7 \%$, respectively. The main reason is that the slagging sample in the reaction tower contains a large amount of carbonate $\left(\mathrm{CaCO}_{3}, \mathrm{Na}_{2} \mathrm{CO}_{3}\right)$. When XRF analysis is carried out, only $\mathrm{Ca}$ and $\mathrm{Na}$ are considered, and the remaining content of $\mathrm{CO}_{3}$ (release as $\mathrm{CO}_{2}$, named as loss on ignition (LOI)) is not considered, resulting in a larger weight fraction of $\mathrm{Ca}$ and $\mathrm{Na}$. The all $\mathrm{CO}_{2}$ in the RT are assumed to come from $\mathrm{CaCO}_{3}$ and $\mathrm{Na}_{2} \mathrm{CO}_{3}$ and the weight fraction of $\mathrm{CO}_{2}$ can be determined by that of $\mathrm{CaO}$ and $\mathrm{Na}_{2} \mathrm{O}$. The real contents of $\mathrm{Ca}$ and $\mathrm{Na}$ in the slagging sample can be obtained after conversion by the following formulas:

$W_{\mathrm{Ca}}(\%)=\frac{W_{\mathrm{CaO}}}{100+M_{\mathrm{CO}_{2}}\left(\frac{W_{\mathrm{CaO}}}{M_{\mathrm{CaO}}}+\frac{W_{\mathrm{Na}_{2} \mathrm{O}}}{M_{\mathrm{Na}_{2} \mathrm{O}}}\right)} \frac{M_{\mathrm{Ca}}}{M_{\mathrm{CaO}}}$

$W_{\mathrm{Na}}(\%)=\frac{W_{\mathrm{Na}_{2} \mathrm{O}}}{100+M_{\mathrm{CO}_{2}}\left(\frac{W_{\mathrm{CaO}}}{M_{\mathrm{CaO}}}+\frac{W_{\mathrm{Na}_{2} \mathrm{O}}}{M_{\mathrm{Na}_{2} \mathrm{O}}}\right)} \frac{2 M_{\mathrm{Na}}}{M_{\mathrm{Na}_{2} \mathrm{O}}}$

where $W$ presents the weight fraction; Mpresents the relative atomic mass: $M_{C}=12 ; M_{O}=16 ; M_{N a}=23 ; M_{C a}=40$. The results are shown as black solid squares and circles in Fig. 6 . The contents of $\mathrm{Ca}$ and $\mathrm{Na}$ determined after considering released $\mathrm{CO}_{2}$ are $20 \%$ and $13.4 \%$, respectively and the results are basically consistent with the results obtained by the extraction experiment. This also shows that the AAEM carbonates are the main components in the slagging sample from the RT.

\subsection{Analysis of the migration paths of AAEMs during incineration}

Fig. 7 illustrates the release and migration paths of AAEMs, which can be predicted based on some conclusions provided by other researchers and our experimental results. At the beginning of incineration, a large proportion of $\mathrm{Ca}, \mathrm{Na}$, and $\mathrm{K}$ are released as gaseous metallic calcium, sodium, and potassium from raw materials, such as $\mathrm{CaCl}_{2}, \mathrm{NaCl}$, and $\mathrm{KCl}$. Meanwhile, a small amount of AAEMs can react with silicon and aluminum oxides, etc. to form Cadiopsides and gehlenite and Na- (or K-) aluminosilicates, which can adhere to the furnace. The gaseous AAEM chlorides can react with

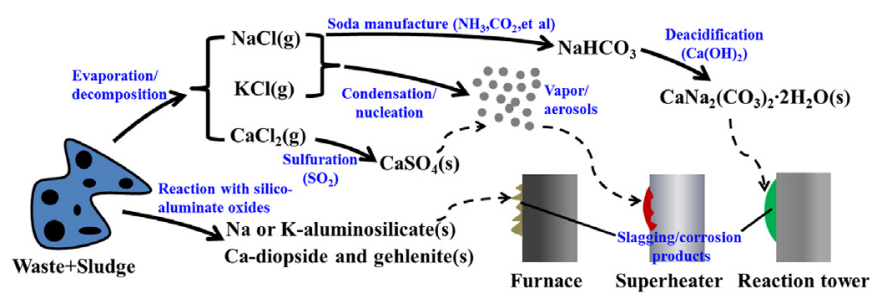

Fig. 7. Mechanisms of $\mathrm{Na}, \mathrm{K}$ and $\mathrm{Ca}$ transformation, condensation and corrosion.

$\mathrm{SO}_{2}$ to form AAEM sulfates in the oxidizing atmosphere when the temperature reaches the melting point of the reactants. When AAEM chlorides and sulfates leave the furnace and enter the waste heat boiler, the AAEM vapors or aerosols can condense onto the surface of the superheaters as gas temperature decreased, which will cause slagging and corrosion phenomenon. In addition, when some uncondensed $\mathrm{NaCl}$ enters the reaction tower, in which $\mathrm{NH}_{3}$ and $\mathrm{CO}_{2}$ are present, the process for soda manufacture is carried out and generates $\mathrm{NaHCO}_{3}$. The lime slurry $\left(\mathrm{Ca}(\mathrm{OH})_{2}\right)$ added in the deacidification process will react with baking soda $\left(\mathrm{NaHCO}_{3}\right)$ to form pirssonite $\left(\mathrm{CaNa}_{2}\left(\mathrm{CO}_{3}\right)_{2} \cdot 2 \mathrm{H}_{2} \mathrm{O}\right)$, which can contribute to the slagging phenomenon in reaction tower.

The above results show that $\mathrm{Cl}$ and $\mathrm{S}$ in the raw materials have an important influence on the release of AAEMs. The content of ash rich in $\mathrm{Cl}$ and $\mathrm{S}$ increases with the addition of sludge and the release of AAEMs is promoted, thereby enhancing the problem of slagging and corrosion caused by AAEMs. Therefore, the pretreatment of sludge is an effective way to solve this problem. In this paper, the treatment method of sewage sludge is sludge granulation [51,52], which can be achieved by a granulator. As shown in Fig. 8, the furnace running time of different feeding methods is counted in the actual plant and the difference between average running time and maximum time or minimum time is used as the uncertainty. It can be found that there is a significant difference in the running time due to the slagging problem by comparing three incinerators using different raw materials, for example, pure waste incineration is approximately $7-13$ months, waste and sludge is $2-4$ months, and waste and granulated sludge is $4-8$ months. These results show that sludge granulation can significantly increase the furnace running time. The main reason can be considered that sludge granulation reduces the mutual contact area between sludge and waste during incineration, and thus reduces the chances of $\mathrm{Cl}$ and AAEMs forming chlorides. Therefore, the release of AAEMs is

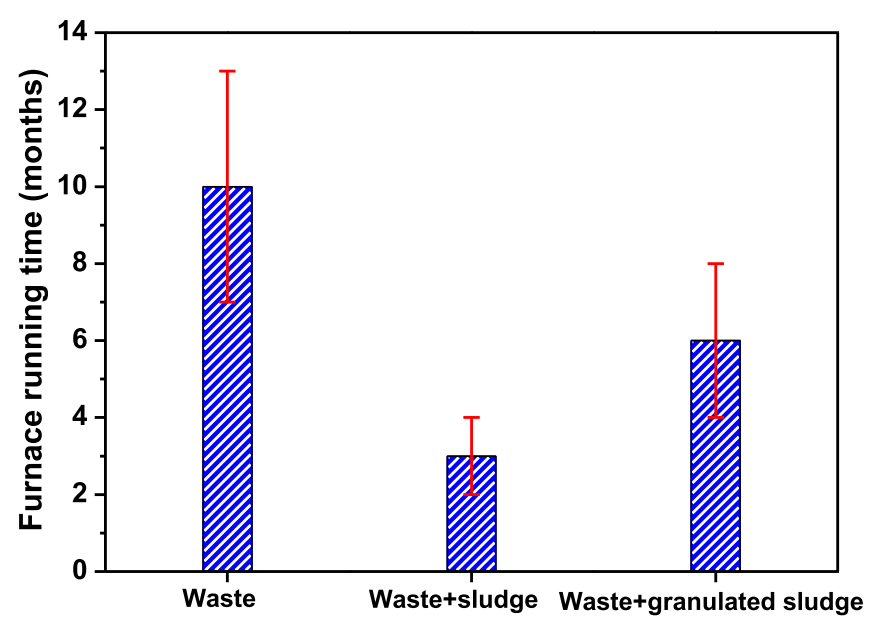

Fig. 8. Furnace running time caused by slagging for three different feeding methods. 
inhibited during incineration, and the slagging and corrosion problems caused by AAEMs are also weakened. In addition, the weight of sludge is increased after granulation, which can reduce the quantity of ash entrained by flue gas. Finally, the additives in the sludge granulation process may also inhibit the release of AAEMs. As a result, the running time can be extended.

\section{Conclusions}

In this paper, the slagging mechanisms caused by AAEMs during MSW and sewage sludge co-incineration are systematically studied through extraction experiments and characterization methods. The slagging samples obtained from four typical positions, named as furnace, high-temperature superheater, medium-temperature superheater and reaction tower, are selected to indirectly reveal the transformation and deposition mechanisms of AAEMs. Furthermore, the effect mechanisms of sludge granulation on the release of AAEMs and furnace running time are analyzed through comparing three different feeding methods. The main conclusions can be shown as:

(1) The AAEMs mainly present insoluble forms, such as diopside $\left(\mathrm{Ca}_{2} \mathrm{MgFeSi}_{4} \mathrm{O}_{12}\right)$, gehlenite $\left(\mathrm{Ca}_{2} \mathrm{MgAl}_{2} \mathrm{Si}_{2} \mathrm{O}_{10}\right)$ and sodium and potassium aluminosilicates $\left(\mathrm{NaAlSi}_{2} \mathrm{O}_{6}, \mathrm{KAISi}_{2} \mathrm{O}_{6}\right)$, in the furnace, as determined by crystalline analysis results by XRD. The alkaline earth metal (Ca) primarily presents in ammonium acetate-soluble form as $\mathrm{CaSO}_{4}$, and the alkali metals ( $\mathrm{Na}$ and $\mathrm{K}$ ) are primarily in water-soluble form as $\mathrm{NaCl}$ and $\mathrm{KCl}$ in the superheaters. In reaction tower, pirssonite (CaN$\left.\mathrm{a}_{2}\left(\mathrm{CO}_{3}\right)_{2} \cdot 2 \mathrm{H}_{2} \mathrm{O}\right)$ and $\mathrm{Na}_{2} \mathrm{CO}_{3} \cdot \mathrm{H}_{2} \mathrm{O}$ are the main existence forms.

(2) The AAEMs in waste mainly release in the form of gaseous $\mathrm{CaCl}_{2}, \mathrm{NaCl}$ and $\mathrm{KCl}$. Meanwhile, a small amount of AAEMs can react with silicon and aluminum oxides, etc. to form aluminosilicates, which can adhere to the furnace. The gaseous AAEM chlorides can also react with $\mathrm{SO}_{2}$ to form AAEM sulfates, which can cause slagging phenomenon on the high-temperature surface of superheaters. Compared with HTS, the content of ammonium acetate-soluble Ca increases approximately $21 \%$ in the MTS. In addition, when some uncondensed $\mathrm{NaCl}$ enters the reaction tower, the slagging phenomenon will occur under the combined action of soda manufacture and deacidification process.

(3) During MSW and sewage sludge co-incineration, sludge granulation inhibits the release of AAEMs via reducing mutual contact area between sludge and waste, increasing the weight of sludge and adding additives. The slagging and corrosion problems caused by AAEMs are also weakened. The results show that sludge granulation can significantly increase the running time. Pure waste incineration is approximately 7-13 months, the co-incineration of waste and sludge is $2-4$ months, as well as the co-incineration of waste and granulated sludge is $4-8$ months.

\section{Declaration of competing interest}

The authors declare that they have no known competing financial interests or personal relationships that could have appeared to influence the work reported in this paper.

\section{CRediT authorship contribution statement}

Jing Zhao: Methodology, Software, Validation, Formal analysis, Investigation, Data curation, Writing - original draft. Xiaolin Wei:
Conceptualization, Supervision, Methodology. Yufeng Zhang: Data curation, Visualization, Software. Teng Li: Conceptualization, Methodology, Supervision.

\section{Acknowledgements}

This work is supported by the National Natural Science Foundation of China (No.51736010). The authors also thank the plant for supplying raw materials and some data.

\section{Nomenclature}

\section{MSW municipal solid waste}

AAEMs alkali and alkaline earth metals

SEM-EDS scanning electron microscopy-energy dispersive

spectrometry

XRF X-ray fluorescence

XRD X-ray diffraction

FU furnace

HTS high-temperature superheater

MTS medium-temperature superheater

RT reaction tower

RSD relative standard deviation

LOI Loss on ignition

Symbols

W weight fraction (\%)

$M \quad$ relative atomic mass

\section{References}

[1] Zhao YY, Zhan JY, Liu GR, Ren ZY, Zheng MH, Jin R, et al. Field study and theoretical evidence for the profiles and underlying mechanisms of PCDD/F formation in cement kilns co-incinerating municipal solid waste and sewage sludge. Waste Manage 2017;61:337-44.

[2] Chin S, Jurng J, Lee JH, Hur JH. Oxygen-enriched air for co-incineration of organic sludges with municipal solid waste: a pilot plant experiment. Waste Manage 2008;28(12):2684-9.

[3] Zhai YB, Peng C, Xu BB, Wang TF, Li CT, Zeng GM, Zhu Y. Hydrothermal carbonization of sewage sludge for char production with different waste biomass: effects of reaction temperature and energy recycling. Energy 2017; $127: 167-74$

[4] Liu ZQ Liu ZH, Li XL. Status and prospect of the application of municipal solid waste incineration in China. Appl Therm Eng 2006;26(11-12):1193-7.

[5] Lai ZY, Ma XQ Tang YT, Lin H. A study on municipal solid waste (MSW) combustion in $\mathrm{N}_{2} / \mathrm{O}_{2}$ and $\mathrm{CO}_{2} / \mathrm{O}_{2}$ atmosphere from the perspective of TGA. Energy 2011;36(2):819-24.

[6] Shen BX, Lei Q. Study on MSW catalytic combustion by TGA. Energ Convers Manage 2006;47(11-12):1429-37.

[7] You SM, Wang W, Dai YJ, Tong YW, Wang CH. Comparison of the cogasification of sewage sludge and food wastes and cost-benefit analysis of gasification- and incineration-based waste treatment schemes. Bioresource Technol 2016;218:595-605.

[8] Zha JR, Huang YJ, Xia WQ Xia ZP, Liu CQ, Dong L, Liu LQ. Effect of mineral reaction between calcium and aluminosilicate on heavy metal behavior during sludge incineration. Fuel 2018;229:241-7.

[9] Hu HY, Zhang X, Liu H, Chen DK, Li AJ, Yao H, et al. Mechanism of chromium oxidation by alkali and alkaline earth metals during municipal solid waste incineration. P Combust Inst 2015;35(2):2397-403.

[10] Zhang H, He PJ, Shao LM. Fate of heavy metals during municipal solid waste incineration in Shanghai. J Hazard Mater 2008;156(1-3):365-73.

[11] Wunsch P, Greilinger C, Bieniek D, Kettrup A. Investigation of the binding of heavy metals in thermally treated residues from waste incineration. Chemosphere 1996;32(11):2211-8.

[12] Bashir MS, Jensen PA, Frandsen F, Wedel S, Dam-Johansen K, Wadenbäck J, Pedersen ST. Ash transformation and deposit build-up during biomass suspension and grate firing: full-scale experimental studies. Fuel Process Technol 2012;97(97):93-106.

[13] Yoffe O, Wohlfarth A, Nathan Y, Cohen S, Minster T. Oil shale fueled FBC power plant-ash deposits and fouling problems. Fuel 2007;86(17):2714-27.

[14] Nielsen HP, Baxter LL, Sclippa G, Morey C, Frandsen FJ, Dam-Johansen K. Deposition of potassium salts on heat transfer surfaces in straw-fired boilers: a pilot-scale study. Fuel 2000;79(2):131-9.

[15] Frandsen FJ. Utilizing biomass and waste for power productionda decade of contributing to the understanding, interpretation and analysis of deposits and 
corrosion products. Fuel 2005;84(10):1277-94.

[16] Han J, Xu MH, Yao H, Furuuchi M, Sakano T, Kim HJ. Influence of calcium chloride on the thermal behavior of heavy and alkali metals in sewage sludge incineration. Waste Manage 2008;28(5):833-9.

[17] Wang JR, Chen FM, Zhao B, Li XJ, Qin L. Volatilisation and transformation behavior of sodium species at high temperature and its influence on ash fusion temperatures. Fuel Process Technol 2017;155:209-15.

[18] Abbas Z, Moghaddam AP, Steenari BM. Release of salts from municipal solid waste combustion residues. Waste Manage 2003;23(4):291-305.

[19] Wu DY, Wang YH, Wang Y, Li S, Wei XL. Release of alkali metals during cofiring biomass and coal. Renew Energ 2016;96:91-7.

[20] Glarborg P, Marshall P. Mechanism and modeling of the formation of gaseous alkali sulfates. Combust Flame 2005;141(1-2):22-39.

[21] Jiang FH, Zhang SY, Huang XH, Wang CW, Li H, Zhang YF. Sodium vapor capture by coal ash during sodium-rich coal combustion. Appl Therm Eng 2019;161:114-27.

[22] Capablo J, Ballester J. Experimental study of the kinetics of sulfation of alkali chloride deposits. Fuel Process Technol 2015;140:215-21.

[23] Pyykönen J, Jokiniemi J. Modelling alkali chloride superheater deposition and its implications. Fuel Process Technol 2003;80(3):225-62.

[24] Rosner DE, Nagarajan R. Transport-induced shifts in condensate dew-point and composition in multicomponent systems with chemical reaction. Chem Eng Sci 1985;40(2):177-86.

[25] Yu J, Qiao Y, Sun LS, Jin LM, Wang WX, Ma C. Detoxification of ashes from a fluidized bed waste incinerator. Chemosphere 2015;134:346-54.

[26] Tortosa Masiá AA, Buhre BJP, Gupta RP, Wall TF. Characterising ash of biomass and waste. Fuel Process Technol 2007;88(11-12):1071-81.

[27] Lebel F, Rapin C, Mareche JF, Podor R, Chaucherie X, Guernion PY, Brossard JM. Development of a laboratory-scale pilot for studying corrosion on MSWI heat exchangers. Mater Sci Forum 2008;595-598:271-80.

[28] Brossard JM, Diop I, Chaucherie X, Nicol F, Rapin C, Vilasi M. Superheater fireside corrosion mechanisms in MSWI plants: lab-scale study and on-site results. Mater Corros 2011;62(6):543-8.

[29] Naqvi SR, Tariq R, Hameed Z, Ali I, Taqvi SA, Naqvi M, Niazi MBK, Noor T, Farooq W. Pyrolysis of high-ash sewage sludge: thermo-kinetic study using TGA and artificial neural networks. Fuel 2018;233:529-38.

[30] Van Lith SC, Alonso-Ramírez V, Jensen PA, Frandsen FJ, Glarborg P. Release to the gas phase of inorganic elements during wood combustion. Part 1: development and evaluation of quantification methods. Energ Fuel 2006;20(3):964-78.

[31] Liu YQ, Cheng LM, Zhao YG, Ji JQ, Wang OH, Luo ZY. Transformation behavior of alkali metals in high-alkali coals. Fuel Process Technol 2018;169:288-94.

[32] Otsuka N. A thermodynamic approach on vapor-condensation of corrosive salts from flue gas on boiler tubes in waste incinerators. Corros Sci 2008;50(6):1627-36.

[33] Shinata Y. Accelerated oxidation rate of chromium induced by sodium chloride. Oxid Met 1987;27(5-6):315-32.

[34] Lin H, Ma XQ. Simulation of co-incineration of sewage sludge with municipal solid waste in a grate furnace incinerator. Waste Manage 2012;32:561-7.

[35] Poole D, Argent BB, Sharifi VN, Swithenbank J. Prediction of the distribution of alkali and trace elements between the condensed and gaseous phases in a municipal solid waste incinerator. Fuel 2008;87:1318-33.

[36] Yang YM, Wu YX, Zhang H, Zhang M, Liu Q, Yang HR, Lu JF. Improved sequential extraction method for determation of alkali and alkaline earth metals in Zhundong coals. Fuel 2016;181:951-7.

[37] Reichelt J, Pfrang-Stotz G, Bergfeldt B, Seifert H, Knapp P. Formation of deposits on the surfaces of superheaters and economisers of MSW incinerator plants. Waste Manage 2013;33(1):43-51.

[38] Kostakis G. Mineralogical composition of boiler fouling and slagging deposits and their relation to fly ashes: The case of Kardia power plant. J Hazmad Mater 2011;185(2-3):1012-8.

[39] Hu BH, Huang QX, Buekens A, Chi Y, Yan JH. Co-gasification of municipal solid waste with high alkali coal char in a three-stage gasifier. Energ Convers Manage 2017;153:473-81.

[40] Zhao J, Wei XL, Li T, Li HX, Bin F. Behavior of alkali metals in fly ash during waste heat recovery for municipal solid waste incineration. Energ Fue 2018;32(4):4417-23.

[41] Benson SA, Holm PL. Comparison of inorganics in three low-rank coals. Ind Eng Chem Res 1985;24(1):145-9.

[42] Yu J, Qiao Y, Jin LM, Ma C, Paterson N, Sun LS. Removal of toxic and alkali alkaline earth metals during co-thermal treatment of two types of MSWI fly ashes in China. Waste Manage 2015;46:287-97.

[43] Chen GY, Zhang N, Ma WC, Rotter VS, Wang Y. Investigation of chloride deposit formation in a 24 MWe waste to energy plant. Fuel 2015;140:317-27.

[44] Song GL, Song WJ, Qi XB, Lu QG. Transformation characteristics of sodium of zhundong coal combustion/gasification in circulating fluidized bed. Energ Fuel 2016;30(4):3473-8.

[45] Oleschko H, Schimrosczyk A, Lippert H, Müller M. Influence of coal composition on the release of $\mathrm{Na}-, \mathrm{K}-, \mathrm{Cl}-$, and S-species during the combustion of brown coal. Fuel 2007:86(15):2275-82.

[46] Qi XB, Song GL, Song WJ, Lu QG. Influence of sodium-based materials on the slagging characteristics of Zhundong coal. J Energy Inst 2017;90(6):914-22.

[47] Okuno T, Sonoyama N, Hayashi JI, Li CZ, Sathe C, Chiba T. Primary release of alkali and alkaline earth metallic species during the pyrolysis of pulverized biomass. Energ Fuel 2005;19(5):2164-71.

[48] Phongphiphat A, Ryu C, Finney KN, Sharifi VN, Swithenbank J. Ash deposit characterisation in a large-scale municipal waste-to-energy incineration plant. J Hazard Mater 2011;186(1):218-26.

[49] Hillier S. Accurate quantitative analysis of clay and other minerals in sandstones by XRD: comparison of a Rietveld and a reference intensity ratio (RIR) method and the importance of sample preparation. Clay Miner 2000;35(1): 291-302.

[50] Du SL, Wang XH, Shao JG, Yang HP, Xu GF, Chen HP. Releasing behavior of chlorine and fluorine during agricultural waste pyrolysis. Energy 2014;74: 295-300.

[51] Hulshoff Pol LW, de Castro Lopes SI, Lettinga G, Lens PNL. Anaerobic sludge granulation. Water Res 2014;38(6):1376-89.

[52] Kijo-Kleczkowska A, Sroda K, Kosowska-Golachowska M, Musial T, Wolski K. Mechanisms and kinetics of granulated sewage sludge combustion. Waste Manage 2015;46:459-71. 